\title{
Special issue dedicated to the memory of Professor Graeme Hugo
}

\author{
Yan $\operatorname{Tan}^{1}$
}

Published online: 10 May 2018

(C) Springer Science+Business Media, LLC, part of Springer Nature 2018

As one of the late Professor Graeme Hugo's PhD students and colleagues at the University of Adelaide, it is a great privilege to edit this Special Issue of Population and Environment in his honour. Professor Hugo, a distinguished Australian demographer and population geographer, passed away on 20 January 2015 following a short battle with lymphoma.

As many of you know, Graeme was a renowned and well-respected academic nationally and internationally, and a wonderful mentor to his colleagues and students (e.g. see Bedford 2015; Connell 2015; Fincher 2016; Dun and Klocker 2017). His scholarly contributions were recognised in many ways during his lifetime. In the survey of International Union for the Scientific Study of Population (IUSSP) members in 2009 by van Dalen and Henkens, he was voted by his peers as the 34th-ranked demographer of all time for the quality of his work. In 2012, he was named an Officer of the Order of Australia (AO) for distinguished service to population research, particularly the study of international migration, population geography and mobility, and for leadership roles with national and international organisations. His outstanding research capacity, his extensive knowledge, and his invaluable and good-spirited advice have been missed greatly by his friends and colleagues in the Department of Geography, Environment and Population in the School of Social Sciences at the University of Adelaide, and in population and environment research communities around the world.

Graeme's research reputation is largely based on his work on migration which has centred around two major themes. The first focused on improving the conceptualisation, measurement, and understanding of the full range of different forms of population mobility in both more- and less-developed nations, as well as between nations. This resulted in the production of a major reference book (Bilsborrow et al. 1997) on migration measurement. The second focused on understanding the causes and impacts of population movement in relation to economic, environmental, and social issues in both origin and destination

Yan Tan

yan.tan@adelaide.edu.au; http://researchers.adelaide.edu.au/profile/yan.tan

1 Department of Geography, Environment and Population, The University of Adelaide, Adelaide, SA 5005, Australia 
communities. This work centred on Australia and Asia (especially Indonesia), but more general contributions on the theories and concepts around circular migration were subsequently developed (e.g. Hugo 1978, 1982, 2008b, c). Graeme was a prolific writer. He crafted 21 books, 208 refereed journal articles, 10 edited books, and 246 book chapters. His work has been cited 26,098 times, with an $h$-index of 64 and i10-index of 309, in Google Scholar as of 30 April 2018. One of his publications with Massey and other colleagues 'Theories of international migration: a review and appraisal' in Population and Development Review (Massey et al. 1993) has received 5423 citations to date.

Graeme had a strong interest in the role of the environment as a cause and consequence of migration. He was one of the first writers to address the complex interface between migration and environment - an area that has previously been greatly neglected in both areas of research. His article in the International Migration Review in 1996 on migration and environment (Hugo 1996) has been recognised as one of the first to draw attention to environmentally induced migration and especially the potential impacts of climate change. In 2008, he was invited by the International Organisation of Migration (IOM) to update and expand the paper, as part of their new thrust to increase awareness of the potential for migration as a result of climate change (Hugo 2008a). Graeme was involved in a number of major research initiatives and projects as part of the growing concern about climate change and its likely impact on migration and adaptation. These included an invitation in 2008 by the Migration Program of the Social Science Research Council in New York to prepare and present a paper on environment and migration as part of their program on new issues in global international migration; participation in an invited expert group organised by the United Nations University and the IOM to develop policy-related research agenda on migration and climate change in 2008 and 2009; and heading a research team, of which I was part of, which subsequently won a US\$200k Asian Development Bank (ADB) project to survey migration and climate change in the Asia-Pacific region. The study was praised by an international expert panel and was partly published by the ADB. In 2010, he was the lead Chief Investigator (CI) for the 5-year Discovery project ' $C$ limate change and migration in China' funded by the Australian Research Council (ARC), under which I was also awarded an ARC Queen Elizabeth II Fellowship. In 2011, he lead another team, in which I was a named CI, in winning another National Category One project funded by the National Climate Change Adaptation Research Facility (NCCARF) to address the impact of climate change on disadvantaged groups in Australia.

For years, Graeme was flying from Australia to meet with and provide advice to policy practitioners at a number of key international organisations, in particular the United Nations (UN) Population Division, the UN Population Fund (UNFPA), the UN Economic and Social Commission for Asia and the Pacific (ESCAP), the International Labour Organization (ILO), the Joint United Nations Programme on HIV/AIDS (UNAIDS), the World Bank, the Asian Development Bank, and the Population Council in New York. He was also a member of the Consultative Committee of the Nansen Initiative on Population Displacement due to Disasters. During his academic career, he mentored $72 \mathrm{PhD}$ students, 20 MA, and 58 Masters in Population Studies. He had an impact in training scholars from Asia notably in Indonesia, Malaysia, Vietnam, Thailand, Pakistan, Sri Lanka, and Bangladesh. He was a true inspiration for me and for many around the world.

This Special Issue provides a small sample of research that was inspired by Graeme. The collection contains five articles contributed by outstanding, highly influential researchers in the research fields of climate change adaptation, environmental migration, 
and environmental policy. Many of the contributors of the Special Issue worked with Graeme in a close and extensive way. These five articles reveal how Graeme's work has influenced the authors' unique experiences promoting climate change adaptation in relation to migration at the highest international levels. By themselves, these papers are a significant contribution to academic thought, but they also extend the vast intellectual legacy left behind by Graeme; they echo his spirit to always expand intellectual boundaries by questioning the as-yet-unknown.

The lead paper by Gamlen et al. entitled 'The evolution and impacts of Graeme Hugo's environmental migration research' includes co-authors who had worked closely with Graeme over many years. The paper provides a systematic and comprehensive overview of the development and impact of Hugo's research agenda concerning the environmentmigration nexus. Barnett and McMichael's paper 'The effects of climate change on the geography and timing of human mobility' presents three excellent examples of contemporary internal and international migration in the Pacific that have close links to environmental change. As an anonymous reviewer noted, 'this topic was very close to Graeme's heart in the latter years of his unexpectedly fore-shortened life. Not long before he died, he completed a major piece of contract research for Australia's former aid agency, AusAID, on new visa categories for people from coral islands in the central Pacific.' Reflecting on the work by Bardsley and Hugo (2010) that developed a key theory on thresholds of environmental migration, McLeman's paper 'Thresholds in climate migration' discusses the six types of thresholds that have been observed in response to climate (environmental) change. It is an important addition to the literature by filling some of the theoretical gaps and providing substantive insights guiding empirical efforts to identify, describe, and test for nonlinearities and tipping points. Drawing from the author's work experience and extensive knowledge base, Warner's paper 'A more coordinated approach to large scale movements of people: Contributions of the Paris Agreement and the Global Compacts for migration and on refugees' provides a thorough account of the progress being made around climate-related migration and displacement within the broad process and mechanisms of the UN Framework Climate Change Convention (UNFCCC), and of emerging linkages to the Global Compacts on migration and refugees. The study shows how climate change policy (action) and human mobility policy (action) at the global level have influenced each other, and accentuates the implications of their interplay for the international community and affected nations in averting, minimising and managing large-scale movements of people. "The uneven geography of research on "environmental migration", by Piguet, Kaenzig and Guélat, presents the first detailed mapping of research in the field of environmentally induced population mobility. It is an important contribution to the literature on the long-lasting North-South divide in scientific research on climate and migration, providing a context and solid foundation for guiding future research directions into environmental migration.

In closing this editorial, I would like to reflect on a recent significant development that has further recognised Graeme's 24-year legacy at the University of Adelaide. Graeme established and consolidated the Australian Population and Migration Research Centre (APMRC) in 2012 (formerly the National Key Centre for Social Applications of Geographical Information Systems (GISCA) from 1994 to 2012), as a world-leading research institute on population and migration studies. In 2016, it was renamed the Hugo Centre for Migration and Population Research in his memory. Graeme's entire career was dedicated to building and strengthening knowledge of the area of population and migration research, 
both in terms of its theoretical, methodological, and policy dimensions and also through his representation within institutional settings. He had a great impact on research both in the Centre and at the University. The University's current strategic research focus on areas of population, migration, climate change, and sustainable development studies reflects his broader legacy. Our new University Research Strategy, Adelaide Research for Impact 2016-2018 has identified climate change as a priority research area for support, and the core team who have worked with Graeme for many years will continue to build the University's capacity in this area.

Fate has brought me under the wings of Graeme. I have worked closely with Graeme on several major projects in the past 6 years. I was fortunate to have the last meeting with him in his office right before his last Christmas Eve in 2014, after which he was subsequently hospitalised and never came back. I remember him saying to me: 'Yan, we will have a lot of very important and urgent things to do next year. I will be back to office in early January. Let's work together to finalise our journal article, organise our planned workshop in China in March, and hatch plans about our future projects...' I am continually inspired by Graeme's brilliant and extraordinary mind and massive body of work and wish to acknowledge his overarching influence on my own research career.

May your soul rest in peace, Graeme: one of the brightest stars of the Southern Cross.

\section{References}

Bardsley, D. K., \& Hugo, G. J. (2010). Migration and climate change: examining thresholds of change to guide effective adaptation decision-making. Popul Environ, 32(2), 238-262.

Bedford, R. (2015). Obituary: Graeme John Hugo AO, FASSA, 1946-2015. N Z Geogr, 71, 61-62.

Bilsborrow, R. E., Hugo, G., Oberai, A. S., \& Zlotnik, H. (1997). International migration statistics: guidelines for improving data collection systems. Geneva: International Labour Office.

Connell, J. (2015). Obituary: Graeme John Hugo 1946-2015. Aust Geogr, 46(2), 271-279.

Dun, O., \& Klocker, N. (2017). Labour and environmental migration in the Asia-Pacific: in memory of Graeme Hugo. Aust Geogr, 48(1), 1-5.

Fincher, R. (2016). Remembering Graeme Hugo, Population Geographer. Aust Geogr, 47(4), 377-382. Hugo, G. (1978). Population Mobility in West Java. Gadjah Mada University Press: Yogyakarta.

Hugo, G. (1982). Circular migration in Indonesia. Population and Development Review, 8(1): 59-83.

Hugo, G. (1996). Environmental concerns and international migration. Int Migr Rev, 30(1), 105-131.

Hugo, G. (2008a). Migration, development and environment. IOM migration research series no 35. Geneva: International Organization for Migration (IOM).

Hugo, G. (2008b). In and out of Australia: rethinking Indian and Chinese skilled migration to Australia. Asian Population Studies, 3(4), 267-291.

Hugo, G. (2008c). Immigrant settlement outside of Australia's capital cities. Population, Space and Place, 14(6), 553-571.

Massey, D. S., Arango, J., Hugo, G., Kouaouci, A., Pellegrino, A., \& Taylor, J. E. (1993). Theories of international migration: a review and appraisal. Popul Dev Rev, 19(3), 431-466. 